\title{
Influence of Direct Splat-Affecting Parameters on the Splat-Type Distribution, Porosity, and Density of Segmentation Cracks in Plasma-Sprayed YSZ Coatings
}

\author{
W. Tillmann ${ }^{1} \cdot$ O. Khalil ${ }^{1} \cdot$ I. Baumann ${ }^{1}$
}

Submitted: 30 November 2020/in revised form: 5 February 2021/ Accepted: 8 February 2021/Published online: 18 March 2021 (C) The Author(s) 2021

\begin{abstract}
The integrity and properties of ceramic coatings produced by atmospheric plasma spraying are highly controlled by the splat morphology and splat interconnection. In this study, the influence of selected parameters (spray angle, surface velocity of the spray gun, and substrate temperature) on splat morphology and coating microstructure was investigated. A favorite set of spray gun parameters, of which their effects on splat morphology and coating microstructure have been verified by previous experiments, were used to conduct the experiments for the present work. It was found that depositing fully molten particles on a hot substrate increases the fraction of disklike splats by about $60 \%$ at the expense of the fraction of irregular splats. Preheating the substrate also increases the pore count and level of coating porosity, while it does not influence the density of segmentation cracks. In contrast, the surface velocity of the spray gun does not affect the splat morphology while a slow speed decreases the coating porosity and plays a significant role in generating segmentation cracks. Shifting the spray angle by $15^{\circ}$ distorts up to $20 \%$ of disk-like splats and slightly decreases the porosity level. However, changing the spray angle does not affect the generation of segmentation cracks.
\end{abstract}

Keywords atmospheric plasma spray (APS) . segmentation cracks · splat · splat-type distribution . substrate temperature $\cdot$ thermal barrier coating (TBC) . yttria-stabilized zirconia (YSZ)

O. Khalil

omar.khalil@tu-dortmund.de

1 Institute of Materials Engineering, Technische Universität Dortmund, Dortmund, Germany

\section{Introduction}

Thermally sprayed coatings are widely used as functional surfaces for engineering applications to protect them against wear, corrosion, high temperature, oxidation, and heat (Ref 1). For plasma-sprayed ceramic coatings, thermal barrier coatings (TBCs) provide thermal insulation and comply with strains due to the porosity in their top coat, which includes a wide range of sizes and shapes of all voids and cracks. This porosity is generated by the coating formation process, which is usually atmospheric plasma spraying (APS) (Ref 2). In addition, lifetime and strain tolerance are improved by the presence of segmentation cracks in the ceramic top coat. Improvement of the strain tolerance by segmentation cracks can be explained by the opening and closing of the crack spacing during tensile and compressive loadings, respectively, which result in an enhancement of the TBCs' thermal shock resistance (Ref 3-7).

In the APS process, metal or ceramic particles injected into the plasma jet are quickly melted and accelerated towards a prepared substrate where they flatten and rapidly solidify to form splats. Therefore, the formation of plasmasprayed coatings can be seen as a continuous and subsequent impingement and solidification of a large number of varied melting-degree particles that consolidate and form a layered deposit on the substrate surface (Ref 8). The resulting layered deposit characterizes the microstructure and consequently determines the ultimate properties of the coating (Ref 9).

As the splat is the main unit for the build-up of the deposit, coating integrity and properties are highly controlled by splat morphology, splat adherence to the substrate, and interconnection between splats. Semi-molten and distorted types of splats form pores and lead to poor 
adhesion between the coating and the substrate and a low coating consistency, while disk-like type splats reduce pore formation and improve coating integrity (Ref 9). From the viewpoint of splat morphology, the distribution of the splat type, therefore, plays an important role in the quality and properties of plasma-sprayed coatings (Ref 10).

However, splat morphology and contact quality between the splats and the substrate surface as well as the contact quality between contiguous splats (inter-splat), depend mainly on in-flight particle characteristics and substrate/ impingement conditions (Ref 11-13).

Process parameters, such as the plasma arc current, stand-off distance, and plasma gas mixture are the main factors that have a strong and direct effect on the in-flight particle characteristics (melting degree and particle temperature and velocity), while they indirectly affect the splat-type distribution. Hence, from the viewpoint of splat formation, we call them "indirect splat-affecting parameters".

It has been reported that the quality of an APS ceramic coating is directly connected to the melting state of the particles as they impinge on the substrate and the resulting splat type distribution. Spray distance and plasma arc current are the most significant process parameters affecting particle melting degree and the fraction value of each splat type (Ref 14, 15). Short spray distance and high plasma arc current at sufficient plasma gas mixture maximize the number of fully molten particles, increase the fraction of disk-like splats, and minimize the number of semi-molten particles. These conditions make the disk-like splats eligible to build long, thick, and well-bonded layers with vertical cracks penetrating the whole thickness of the coating layers.

On the other hand, the substrate/impingement conditions, such as substrate temperature, spray angle, and the surface velocity of the spray gun (interchangeably used with gun traverse speed), directly affect the process of splat formation (Ref 16) and the generation of segmentation cracks. Hence, they are here referred to as "direct splataffecting parameters".

Many researchers have reported qualitatively on the strong influence of the substrate temperature on the morphology of splats (Ref 17-20) and the generation of segmentation cracks (Ref 5, 6, 21-25). An irregular, fragmented splat type is the dominant type if fully molten particles have been deposited on a cold substrate, i.e., a substrate at room temperature. At a certain substrate temperature, known as the "transition temperature", the dominating splat shape changes from fragmented to disklike (Ref 26). This is related to the existence of absorbates and condensates on the substrate surface at lower temperatures, which induce the splashing of splats during droplet flattening (Ref 1,27). This splashing behavior of droplets during spreading can be further induced by the particle impact conditions, such as the impact angle (Ref 28, 29).

Leger et al. (Ref 30) reported that the cooling rate for zirconia particles deposited on a hot substrate $(573 \mathrm{~K})$ is much higher than that when the particles are deposited on a cold substrate $(348 \mathrm{~K})$. They showed that a higher degree of splat flattening on a hot substrate leads to decreasing the splat thickness and increasing the contact area of the splats with the underneath material, and, as a result, this leads to a higher cooling rate $(600 \mathrm{~K} / \mu \mathrm{s}$ on a hot substrate and only $140 \mathrm{~K} / \mu \mathrm{s}$ on a cold substrate). However, particles deposited on a hot substrate preserve their liquidity state during spreading to form disk-like splats despite the higher cooling rate.

Bianchi et al. (Ref 18) have shown that depositing zirconia particles on a cold substrate generates fragmented and distorted splats and that a transition substrate temperature of about $300{ }^{\circ} \mathrm{C}$ changes the splat morphology to the disk-like shape. Fukomoto et al. (Ref 19) investigated various metallic splat morphologies deposited on substrates at different temperatures and reported that there is a distinct transition in splat morphology related to the substrate temperature. Syed et al. (Ref 31), Jiang et al. (Ref 32), and Sampath et al. (Ref 33) showed that both the particle energy and substrate temperature significantly affect splat morphology. They reported that increasing the substrate temperature results in a change of the splat morphology from splashed splats with fragments to disk-like-shaped splats, which indicates the complete suppression of splashing during spreading. Dhimanet et al. (Ref 34) introduced a solidification factor concerning significant parameters, such as the substrate temperature, that influence the change in the shape of the splats from fragmented to disk-like. Sakakibara et al. (Ref 35) investigated the effect of the substrate temperature on the morphology of the splats by spraying yttria-stabilized zirconia (YSZ) on a polished stainless-steel substrate. They reported that the temperature range, in which the transition to a disk-like shape takes place, is $150-200^{\circ}$ C. Friis et al. (Ref 23) investigated the effect of the process parameters on the microstructure of APS YSZ coatings and found that the substrate temperature and the spray angle control the generation of segmentation cracks and delamination, respectively.

Karger et al. and Guo et al. (Ref 5,6) produced segmented plasma-sprayed TBC coatings with different densities of segmentation cracks and reported that segmented coatings achieved a better performance in thermal cycling than non-segmented coatings.

Montavon et al. (Ref 36) showed that the spray angle has no significant effect on the flattening of the splats. Instead, it affects the splat geometry and leads to a distorted splat morphology. The present study is part of a 
project that aims to engineer the microstructure of the ceramic top coating of the segmented TBC based on the investigation of the splat-type distribution. The project plan categorizes the process parameters into two groups based on their effect on splat morphology: the parameters of the first group are the indirect splat-affecting parameters, the spray plasma arc current, standoff distance, and flow of plasma gas mixture, while the parameters of the second group are the direct splat-affecting parameters, the substrate temperature, spray angle, and gun traverse speed. The effects of the indirect splat-affecting parameters on the formation of different splat types, the relative fractions of splat types, and the coating porosity and microstructure have been investigated in a previous study, and a suitable set of parameters has been selected (Ref 37). The selected parameters generate a favorable splat-type distribution (about $90 \%$ are fully molten splats and $10 \%$ are semi-molten splats) with a sufficient level of porosity and produced a microstructure that is eligible for the formation of a segmented TBC top coating. In the current study, the influence of the direct splat-affecting parameters (the second group of parameters) on the distribution of the splat morphology, the coating porosity, and the generation of the segmentation cracks has been quantitatively investigated. Eight experiments according to a two-level full factorial $2^{3}$ plan were conducted to reveal the influence of the three parameters, while the selected indirect splat-affecting parameters were kept constant. Further research aspects are required to distinguish the conditions and the most favorable splat distribution to produce an optimized TBC top coating. The results of the previous and current studies will be used in an optimization process (in an upcoming work) to further enhance the characteristics of TBC top coatings.

\section{Materials and Processes}

\section{Sample Preparation and Deposition Process}

For each spray parameter set, three round samples of steel substrates (DIN C45) with a diameter of $40 \mathrm{~mm}$ and a thickness of $5 \mathrm{~mm}$ were grit-blasted on one side, cleaned, and prepared for coating deposition (APS). The fine particle size of the YSZ powder (7YSZ, $+5-22 \mu \mathrm{m}$, fused and crushed; Oerlikon Metco 6051; Pfäffikon, Switzerland) was air plasma-sprayed on the roughened side of the prepared substrates.

The experiments were conducted according to a $2^{3}$ full factorial design of experiment (DoE), in which only the three direct splat-affecting parameters (substrate temperature, spray angle, and gun traverse speed) were varied, while all the other process parameters were kept unchanged. The parameter sets that have been used to deposit the coatings and to collect splats for this study are given in Table 1.

Additionally, round steel substrates $(40 \mathrm{~mm}$ diameter and $5 \mathrm{~mm}$ thickness) were prepared to collect individual splats for each parameter set using a locally designed experimental setup, the beam shutter (Institute of Materials Engineering, Technische Universität Dortmund) (Ref 38). The steel substrates were mirror-polished to $1.0-\mu \mathrm{m}$ roughness to enable impinging droplets to be free-spreading and flattening. The spray gun and beam shutter were programmed so that, when the moving spray gun was exactly in front of the beam shutter, the slit-mask (sliding part) in the beam shutter falls freely. The free fall of the slit-mask allows a time of about $9 \mathrm{~ms}$ for the spray droplets to pass through a 3-mm gap to the prepared mirror-polished substrate that is fixed behind the slit-mask. A SinplexPro 90 APS gun (Oerlikon Metco) with a 9-mm inner diameter nozzle and a single powder feeder was used for the experiments.

\section{Substrate Temperature}

For process parameter sets $5-8$, in which the preset substrate temperature is about $200{ }^{\circ} \mathrm{C}$, the grit blasted and mirror-polished substrates were preheated by a flame torch from the backside of the substrate. A high-temperature infrared thermometer (Voltcraft IR-1000L, -50 to +1000 ${ }^{\circ} \mathrm{C}$; Conrad Electronic SE, Hirschau, Germany), which was recently calibrated, was employed to monitor the temperature of the substrate surface. The final temperature was reached at about $8 \mathrm{~min}$ of heating, and the actual spraying, as well as splat collection, commenced immediately afterward. In each case, only one spray pass over the mirror-polished substrate was performed to produce isolated single splats. Table 1 lists the substrate temperatures at the start and the end of each experiment.

\section{Splat Investigation}

For each parameter set, individual splats were collected and investigated to obtain information about the different splat morphologies, particle melting state, and the spreading behavior for each splat type. The splats were observed by a field-emission scanning electron microscope (FESEM; JSM-7001F; Joel, Freising, Germany). For each splat sample, three different locations (each of area $0.8 \times 0.6$ $\mathrm{mm}^{2}$ ) in the middle of the sample were chosen where the total number of the splats was recorded and the relative splat-type fractions were evaluated. 
Table 1 DoE (APS) spray parameters $(-$ low level, + high level, RT room temperature)

\begin{tabular}{|c|c|c|c|c|}
\hline \multirow[t]{2}{*}{ Experiment no. } & \multirow[t]{2}{*}{ Spray angle, ${ }^{\circ}$} & \multirow{2}{*}{$\begin{array}{l}\text { Gun traverse speed, } \\
\mathrm{m} / \mathrm{s}\end{array}$} & \multicolumn{2}{|c|}{ Substrate temperature, ${ }^{\circ} \mathrm{C}$} \\
\hline & & & Start & End \\
\hline \multicolumn{5}{|c|}{ Spray parameter set: direct splat-affecting parameters } \\
\hline $1(---)$ & Normal, 0 & 1.0 & RT & $250 \pm 15$ \\
\hline $2(-+-)$ & Normal, 0 & 3.0 & $\mathrm{RT}$ & $200 \pm 10$ \\
\hline $3(+--)$ & Shifted, 15 & 1.0 & $\mathrm{RT}$ & $250 \pm 15$ \\
\hline $4(++-)$ & Shifted, 15 & 3.0 & RT & $200 \pm 10$ \\
\hline $5(--+)$ & Normal, 0 & 1.0 & $200 \pm 10$ & $400 \pm 20$ \\
\hline $6(+-+)$ & Shifted, 15 & 1.0 & $200 \pm 10$ & $400 \pm 20$ \\
\hline $7(-++)$ & Normal, 0 & 3.0 & $200 \pm 10$ & $300 \pm 20$ \\
\hline $8(+++)$ & Shifted, 15 & 3.0 & $200 \pm 10$ & $300 \pm 20$ \\
\hline Arc current, A & Standoff distance, $\mathrm{mm}$ & Argon flow (NLPM) & $\mathrm{H}_{2}$ flow (NLPM) & Passe: \\
\hline \multicolumn{5}{|c|}{ Spray parameter set: constant spray parameters } \\
\hline 520 & 115 & 50 & 8 & 10 \\
\hline
\end{tabular}

\section{Microstructure Analysis}

To characterize the microstructure and quantitatively evaluate the porosity level, the pore information, the density of segmentation cracks, and the thickness of the produced coatings, polished cross-sectional metallographic samples, were prepared. A 2D series of FESEM SEM images with different magnification factors for each crosssection were taken for detailed investigations. For the porosity and pore information measurements, ten 2D-images with a size of $1280 \times 960$ pixels along the polished cross-section were randomly captured, but central to the coating's thickness, for each produced coating. The SEM images were magnified at factors $\times 500$ and $\times 800$. Image brightness and contrast settings were kept constant to avoid any influence on the measurement evaluation (working distance: $8-9 \mathrm{~mm}$, accelerating voltage: $20 \mathrm{kV}$ ). Compo mode, in which the contrast between the pores and coating's matrix is improved, was employed to facilitate the image analysis software and accurately detect porosity zones. Image analysis was performed using the Jimage J1.53e software tool (provided by the National Institutes of Health, Bethesda, MD, USA) (Ref 39). Image filtering was applied to remove noise followed by image segmentation using thresholding. The threshold process produces binary images in which the zero-threshold level (black) is assigned to the pores and the one-threshold level (white) assigned to the YSZ solid state.

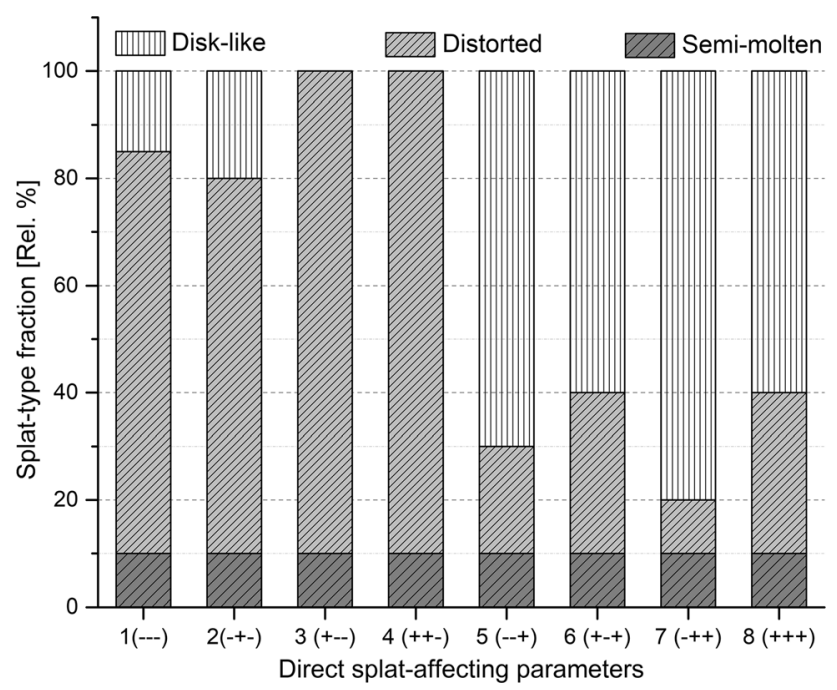

Fig. 1 Influence of direct splat-affecting parameters on the fractions of splat morphology

\section{Results and Discussion}

\section{Influence of Direct Splat-Affecting Parameters on the Splat-Type Distribution}

A splat-type classification has been made, in which three basic types (disk-like, distorted, and semi-molten) were identified, and relative fractions of each splat-type for all cases were evaluated and are presented in Fig. 1. As expected, the ratio of fully molten to semi-molten splats for all the coatings was constant because the same spray gun parameters (standoff distance, current, plasma gas mixture) were used. However, as a result of varying the direct splataffecting parameters as per the full factorial $2^{3}$ design of 
experiment method, the ratio of disk-like to distorted splats (within the fraction of fully molten splats) was considerably changed.

From Fig. 1, it can be seen that the largest fractions of the disk-like splat type, and at the same time, the smallest fractions of the distorted splat type, occur when the substrate was preheated before the deposition was started (onset substrate temperature of $200{ }^{\circ} \mathrm{C}$ ). This condition corresponds to experiments 5-8. In all these cases, the fraction of the disk-like type increases at the expense of the fraction of the distorted type.

The other experiments sprayed on a cold substrate (cases 1-4 sprayed on substrates at room temperature) exhibit the domination of the distorted splat type while the fraction of the disk-like type represents less than $20 \%$ of the total splats. As a result of spraying on a hot substrate, up to $60 \%$ of distorted splats were transitioned to a disk-like type. Additionally, the effect of shifting the spray angle can also be seen; however, in the opposite direction. Up to $20 \%$ of disk-like splats were distorted as a result of shifting the spray angle by $15^{\circ}$ from the normal position which is when the spray axis is perpendicular to the substrate surface, i.e., $0^{\circ}$. This can be seen when comparing splat-type fractions from cases $1,2,5$, and 7 with 3, 4, 6, and 8 .

The statistic software (JMP Pro SAS v.14.2) has been used to analyze in detail the effects of the varied parameters and the effects of their interaction on the distribution of splat-type. Table 2 shows the significance of the varied parameters in descending order concerning the splat type. According to the statistic software, only the substrate temperature and the spray angle qualify as significant factors since their Prob-Value is smaller than 0.05.
While the effect of substrate preheating on the formation of the disk-like splat type is directly proportional, the effect of the spray angle is inversely proportional. The effects of the gun traverse speed and the parameter interactions listed in Table 2 reveal a very low significance and can thus be completely neglected.

The graph in Fig. 2 shows how the splat type fractions are changing by varying the levels of the direct splat-affecting parameters. The highest change is seen by varying the substrate temperature factor followed by the change caused by the spray angle factor while varying the surface velocity of the spray gun has almost no effect.

While deposition on a hot substrate leads to the conversion of considerable amounts of splashed and distorted splats to disk-like type, particles deposited with the spray angle shifted from the normal spray axis lead to distorting the shape of the disk-like splats longitudinally, in which they take an oval shape. The strong effect of substrate preheating is clearly seen in the transition of a large fraction of distorted splats to the disk-like type. Figure 3 shows samples of single splats deposited in the same parameters and conditions on cold and hot substrates.

The effect of the spray angle parameter is considered to be detrimental as the splats collected during shifted spray angle increase the splashing rate of the splats, generating fingers spreading in the direction of the spray axis. Figure 4 shows samples of single splats collected when the deposition is made with normal and shifted spray angles on hot substrates in the same parameters and conditions.

Depositing fully-molten particles with a spray angle of less than $90^{\circ}$ causes droplets to spread in the direction of the spray axis at a higher rate than in the perpendicular
Table 2 Influence of the direct splat-affecting parameters on (a) disk-like, and (b) distorted splat-types

\begin{tabular}{lrrrr}
\hline \multicolumn{1}{c}{ Term } & Estimate & SE & $t$ ratio & Prob $>|t|$ \\
\hline (a) Response: disk-like splats & & & & \\
Substrate temperature $(0,200)$ & $\mathbf{2 9 . 3 7 5}$ & 0.625 & $\mathbf{4 7 . 0 0}$ & $\mathbf{0 . 0 1 3 5}$ \\
Spray angle $(0,15)$ & $\mathbf{- 8 . 1 2 5}$ & 0.625 & $-\mathbf{1 3 . 0 0}$ & $\mathbf{0 . 0 4 8 9}$ \\
Gun traverse speed $(1.0,3.0)$ & 1.875 & 0.625 & 3.00 & 0.2048 \\
Spray angle $\times$ Gun traverse speed & -1.875 & 0.625 & -3.00 & 0.2048 \\
Spray angle $\times$ Substrate temperature & 0.625 & 0.625 & 1.00 & 0.5000 \\
Gun traverse speed $\times$ Substrate & 0.625 & 0.625 & 1.00 & 0.5000 \\
temperature & & & & \\
(b) Response: distorted splats & & & & \\
Substrate temperature $(0$, 200) & $\mathbf{2 9 . 3 7 5}$ & 0.625 & $\mathbf{- 4 7 . 0 0}$ & $\mathbf{0 . 0 1 3 5}$ \\
Spray angle $(0$, 15) & $\mathbf{8 . 1 2 5}$ & 0.625 & $\mathbf{1 3 . 0 0}$ & $\mathbf{0 . 0 4 8 9}$ \\
Gun traverse speed $(1.0,3.0)$ & -1.875 & 0.625 & -3.00 & 0.2048 \\
Spray angle $\times$ Gun traverse speed & 1.875 & 0.625 & 3.00 & 0.2048 \\
Spray angle $\times$ Substrate temperature & -0.625 & 0.625 & -1.00 & 0.5000 \\
Gun traverse speed $\times$ Substrate & -0.625 & 0.625 & -1.00 & 0.5000 \\
temperature & & & & \\
\hline
\end{tabular}

Significant parameters are given in bold 

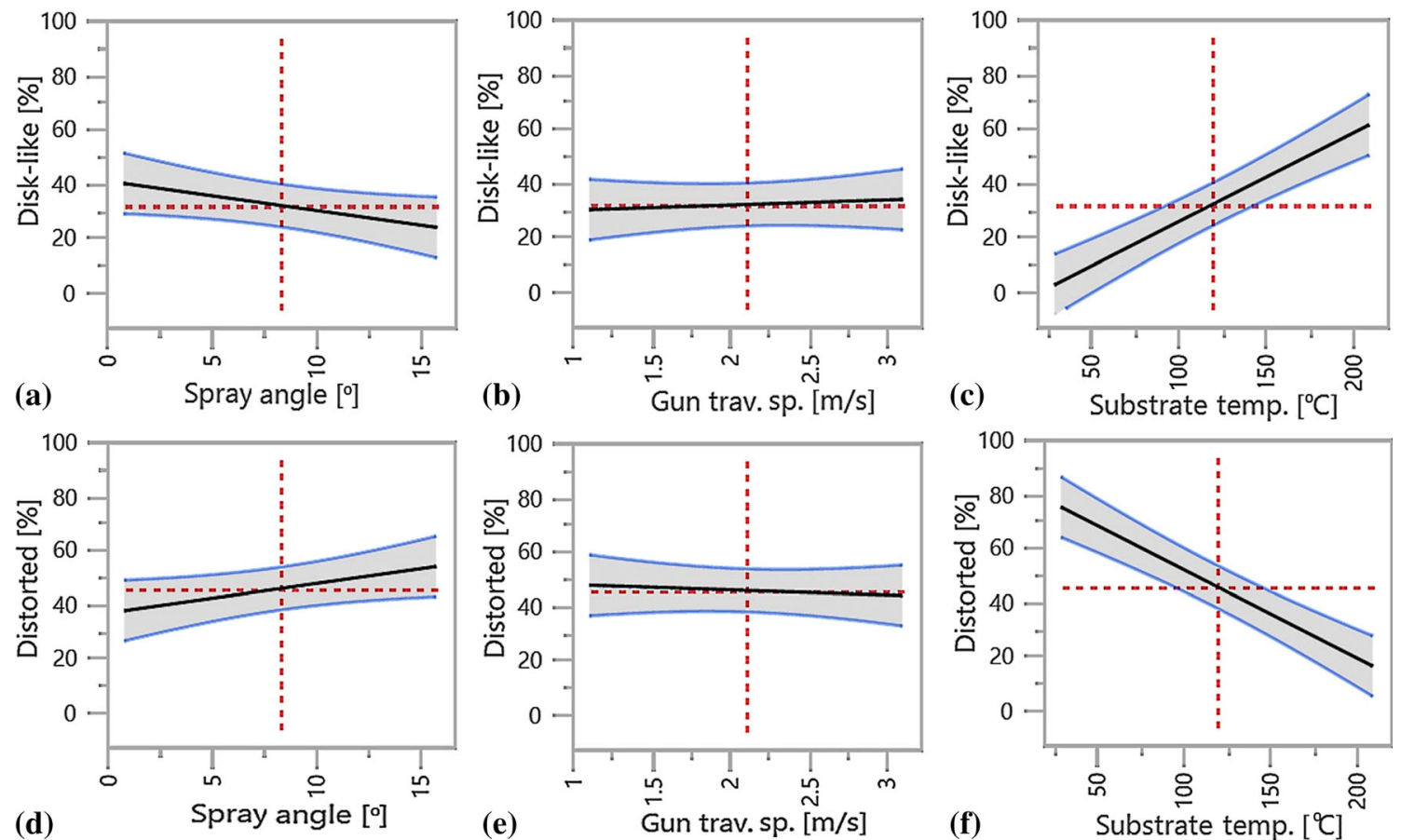

Fig. 2 Prediction profiler of direct splat-affecting parameters on (a, b, and c) disk-like, and (d, e, and f) distorted-splat type fractions
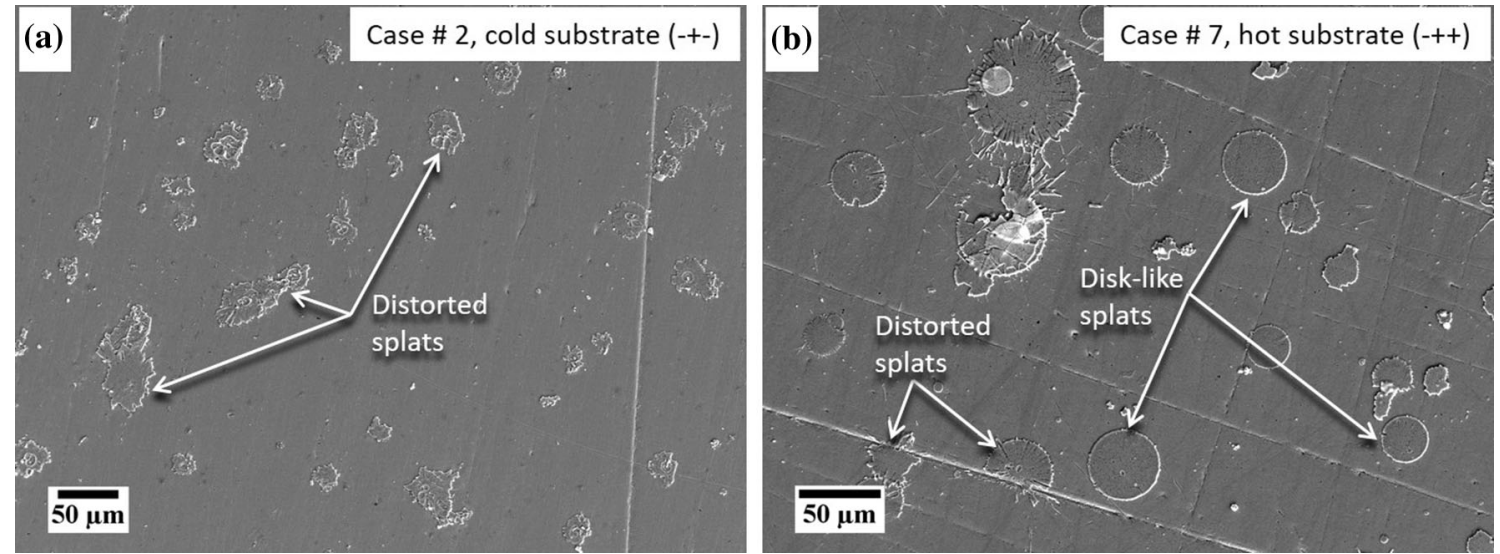

Fig. 3 Single splats deposited on steel substrates at (a) room temperature, (b) $200{ }^{\circ} \mathrm{C}$

direction. This condition leads to produce splats with varying thicknesses. The observed effects of substrate temperature and spray angle on the transitions of splat morphology are in good agreement with the literature data (Ref 18, 19, 31-36).

\section{Effect of Direct Splat-Affecting Parameters on Coating Porosity}

Using the image analysis method, porosity measurements (area\%) were performed on SEM images taken for samples from each case. The arithmetic mean of porosity measurements for all the coatings as well as pore information (pore count and size) were evaluated, and the results are presented in Fig. 5. Generally, the coatings are formed by splat-type distributions that have the same fully molten to semi-molten fractions ratio. Therefore, the porosities were comparable, and their levels were in the range of 4.30-7.95 area\%. However, the condition of whether the disk-like or distorted splat type is the dominant fraction for each distribution implies the increase or decrease in the level of porosity. The effect of substrate temperature on the level of porosity is observable when the porosities of cases 1-4 are compared to the porosities of cases 5-8. In the first cases, the porosities were less than 5.3 area\% when the onset substrate temperature is the room temperature, while the porosities of cases 5-8 were greater than 5.8 area\% when the onset substrate temperature is about $200{ }^{\circ} \mathrm{C}$. Similarly, 

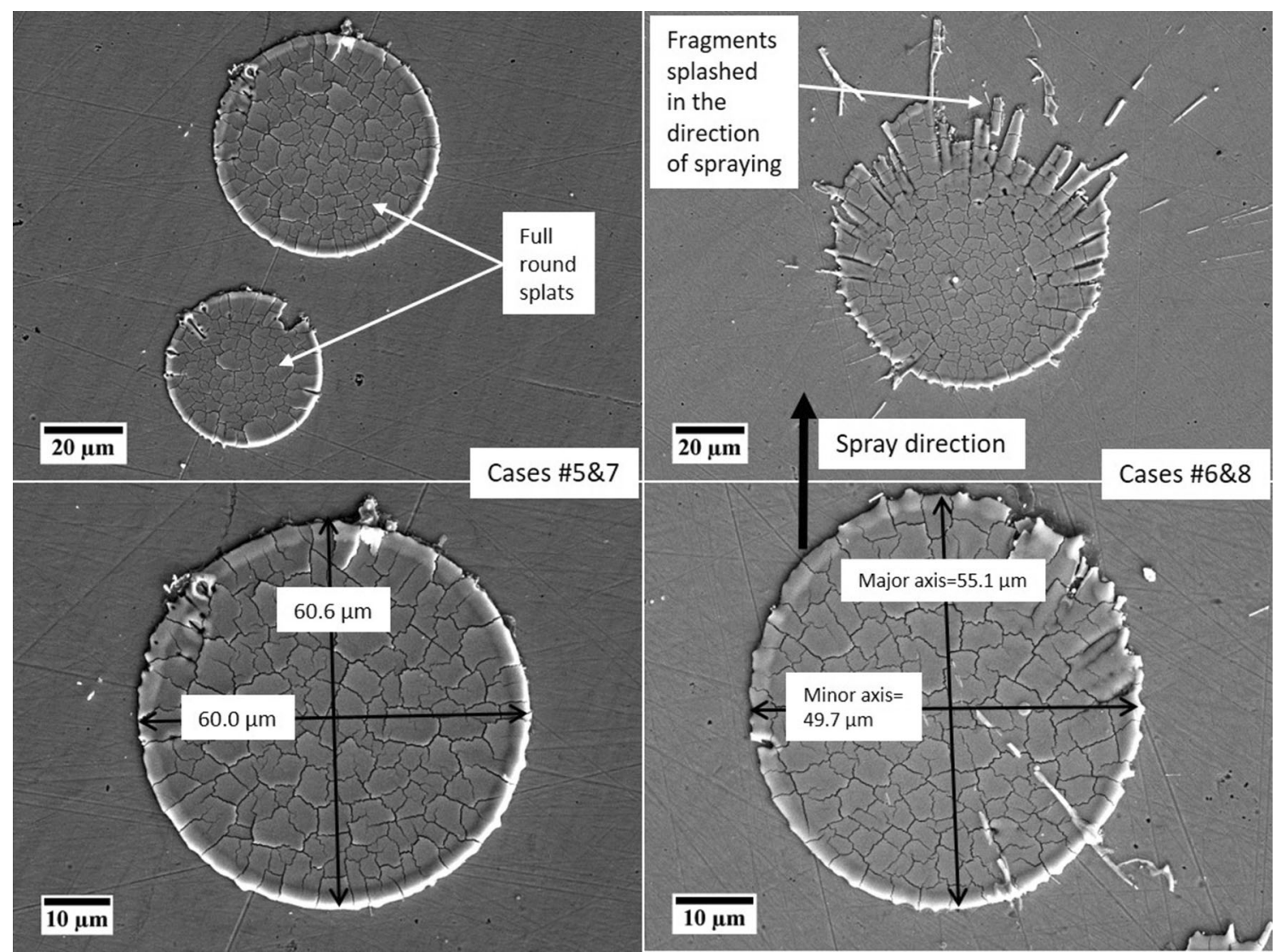

Fig. 4 Single splats deposited on steel substrates with: (left) normal and (right) shifted spray angles

Fig. 5 The dependency of pore size, pore count, and coating porosity on direct splataffecting parameters

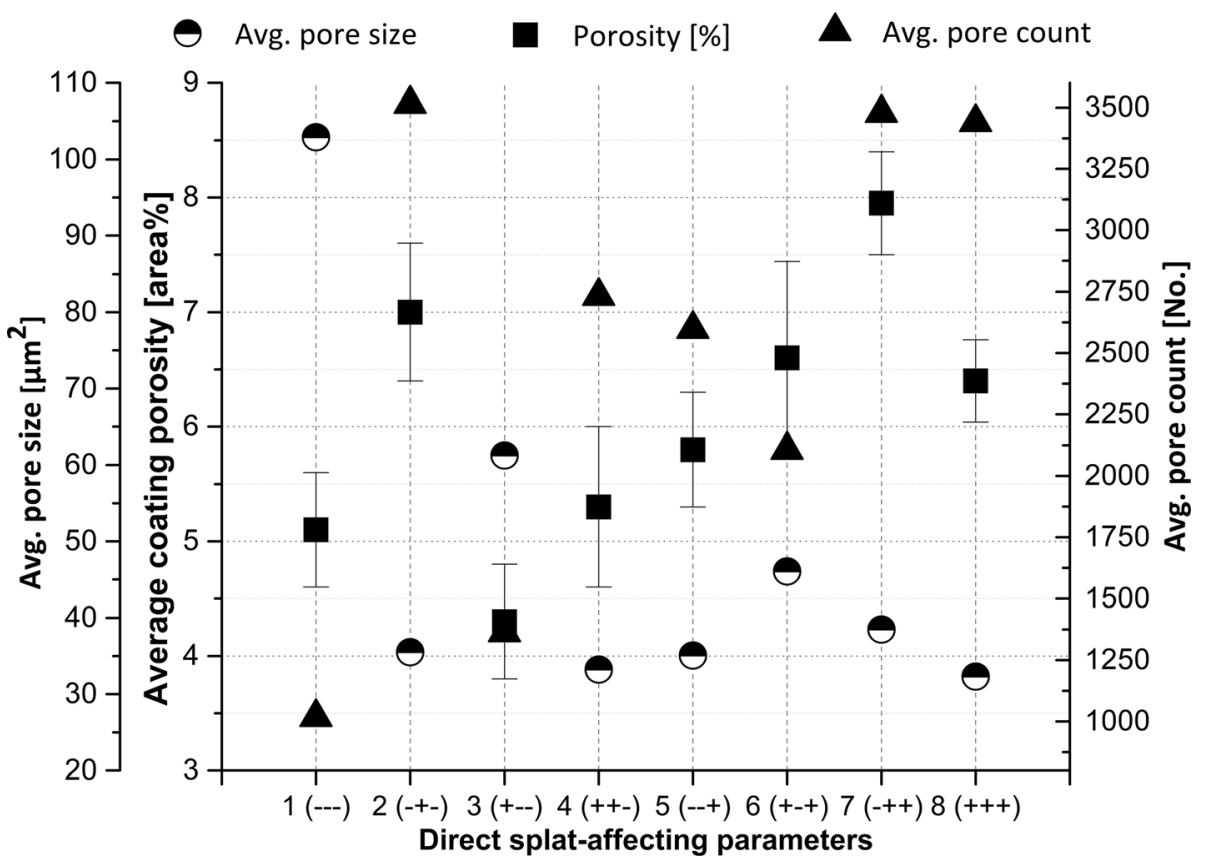

the surface velocity of the spray gun parameter has a comparable effect on the porosity content in cases $2,4,7$, and 8. In these cases, the porosity level is increased due to setting the surface velocity of the spray gun to a high level. 
From Fig. 5, the analyses of pore information show that the pore count is directly proportional to the substrate temperature and the surface velocity of the spray gun and inversely proportional to the spray angle. Coatings obtained either at a high surface velocity of the spray gun (cases 2 and 4) or hot substrates (cases 5 and 6) or both conditions at the same time (cases 7 and 8) show a higher number of the pore count and relatively smaller pore size. Additionally, the pore count is considerably reduced if the spray angle is shifted from normal, i.e., the angle between the surface of the substrate and the spray gun axis is less than $90^{\circ}$ (cases 4, 6, and 8).

In contrast, when both the substrate temperature and the surface velocity of the spray gun are at a low level (i.e., cold substrate and slow surface velocity of the spray gun), the coatings show a lower number of the pore count and relatively large pore size (cases 1 and 3 ).

The increase in the porosity level in the coatings deposited on hot substrates and at a high surface velocity of the spray gun can be attributed to the increase in the fraction of disk-like splats (cases 7 and 8). When fully molten particles are being deposited on a hot substrate, they spread with a high flattening ratio, which allows the formation of only very fine-sized pores. The number of these fine pores is dependent on the surface velocity of the spray gun; the higher the surface velocity of the spray gun, the higher the number of fine pores generated (i.e., a higher level of coating porosity). Additionally, if the particles are deposited at a relatively high surface velocity of the spray gun, then the density of the sprayed splats per unit area is greatly reduced, which leads to the generation of more submicron-sized pores. In contrast, coatings deposited on cold substrates and at a low surface velocity of the spray gun are formed mainly from distorted splats, which generate a low pore count with relatively large pores (cases 1 and 3). Coatings sprayed either on cold substrates at a high surface velocity of the spray gun or on hot substrates at a low surface velocity of the spray gun show moderate levels of porosities (cases 2, 4, 5, and 6). Therefore, if the goal is to produce a coating that has the highest level of porosity with a large number of micropores (average pore size $>5$ $\mu \mathrm{m})$ then the highest fraction of disk-like splats is required. According to the present study, case 7 meets this requirement.

Table 3 lists the varied parameters and their interactions according to the significance of effect in descending order. The effect report reveals that the substrate temperature and surface velocity of the spray gun parameters have considerable and comparable positive effects on the porosity formation, while the spray angle and the interaction of spray angle/surface velocity of the spray gun parameters have a lower and negative effect. However, none of these parameters qualify as significant factors since their ProbValues are greater than 0.05 .

The prediction profiler in Fig. 6 displays how the porosity level changes with varying the direct splat-affecting parameters. The level of porosity is increased considerably by increasing the substrate temperature and the surface velocity of the spray gun parameters (Fig. 6b and c), while it is decreased by shifting the spray angle from normal (Fig. 6a). The profiler can be used to tailoring a coating with a specific porosity level by determining the required values for the direct splat-affecting parameter.

\section{Investigation of Segmentation Cracks and Coating Thickness}

SEM images were taken for the coating cross-sections at different locations to evaluate the average number of segmentation cracks as well as the coating thickness for each case. The results are presented in Fig. 7. Only vertical cracks that have a length of at least half the coating thickness are considered as segmentation cracks. The graph in Fig. 7 shows that the average number of segmentation cracks is equal to or greater than $2.0 \mathrm{cracks} / \mathrm{mm}$ wherever the surface velocity of the spray gun is set to the low level, and independently of the other parameters (cases 1, 3, 5, and 6). Additionally, a slight increase in the number of segmentation cracks is observed when the deposition was made on a hot substrate, as in cases 5 and 6 . It is worth
Table 3 Effect significance of direct splat-affecting parameters on coating porosity

\begin{tabular}{lcccc}
\hline \multicolumn{1}{c}{ Term } & Estimate & SE & $t$ ratio & Prob $>|t|$ \\
\hline Effect report: response: coating porosity & & & & \\
Substrate temperature $(0,200)$ & 0.63125 & 0.18125 & 3.48 & 0.1780 \\
Gun traverse speed $(1.0,3.0)$ & 0.60625 & 0.18125 & 3.34 & 0.1849 \\
Spray angle $(0,15)$ & -0.40625 & 0.18125 & -2.24 & 0.2672 \\
Spray angle $\times$ Gun traverse speed & -0.40625 & 0.18125 & -2.24 & 0.2672 \\
Spray angle $\times$ Substrate & 0.21875 & 0.18125 & 1.21 & 0.4405 \\
temperature & -0.11875 & 0.18125 & -0.66 & 0.6308 \\
Gun traverse speed $\times$ Substrate & & & & \\
temperature & & &
\end{tabular}



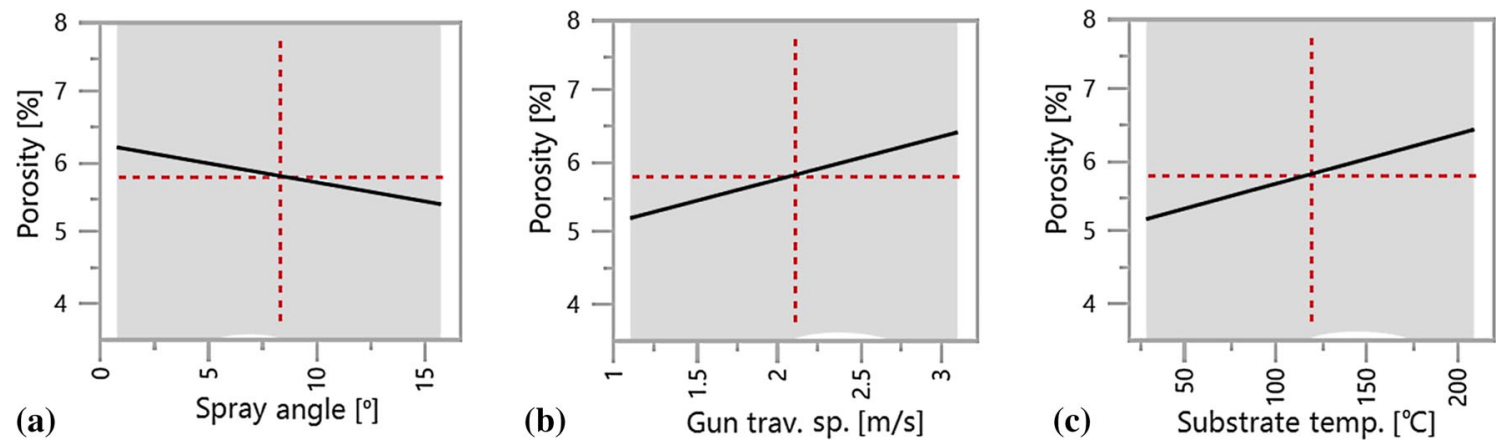

Fig. 6 Prediction profiler of direct splat-affecting parameters on coating porosity

Fig. 7 The average density of segmentation cracks and coating thickness with the standard deviation for coatings deposited at varied direct splat-affecting parameters

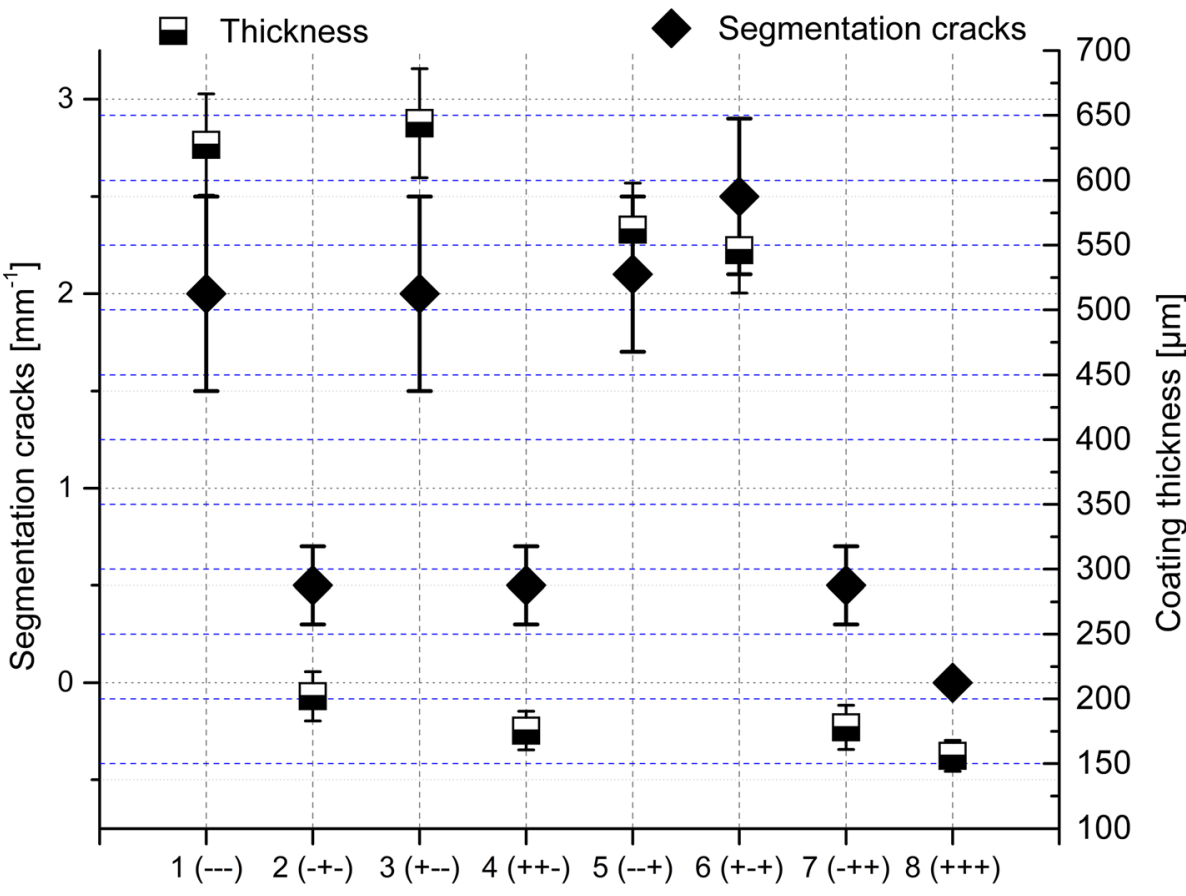

Direct splat-affecting parameters noting here that the slow surface velocity of the spray gun makes the plasma jet traverse the substrate surface for a longer time, which further increases the temperature of the substrate. Therefore, the effect of substrate temperature cannot be ignored and might be considered as a secondary factor in the generation process of segmentation cracks. Since it is not possible to decompose the effects of the surface velocity of the spray gun and substrate temperature as they occur at the same time, the experiments were conducted depending on the onset substrate temperature and not on the substrate temperature during the deposition. Coatings deposited on hot substrates and high surface velocity of the spray gun (cases 7 and 8) exhibit a very low number of segmentation cracks, which indicates the crucial effect of the surface velocity of the spray gun parameter. The effect report and prediction profiler of direct splataffecting parameters are shown in Table 4 and Fig. 8, respectively. The list in Table 4 also indicates the sole effect of the surface velocity of the spray gun, although it does not rise to the level to be considered as a significant factor, because its Prob-Value is greater than 0.05. All the other parameters have almost no effect on the formation of segmentation cracks. The prediction profiler in Fig. $8 \mathrm{~b}$ illustrates the inverse relationship between the surface velocity of the spray gun parameter and the number of generated segmentation cracks. The observable effect of the surface velocity of the spray gun is linked to the large number of fully molten particles per unit area that impinge on the substrate surface during the deposition process due to the slow surface velocity of the spray gun.

The spreading behavior of the dense droplets leads to a lowering of the splat thickness and an increase in the contact area of the splat with the underneath material, and, as a result, to a higher cooling rate. These conditions make 
Table 4 Effect significance of direct splat-affecting parameters on the formation of segmentation cracks

\begin{tabular}{lcccc}
\hline \multicolumn{1}{c}{ Term } & Estimate & SE & $t$ ratio & Prob $>|t|$ \\
\hline Effect report: segmentation cracks & & & & \\
Gun traverse speed $(1.0,3.0)$ & -0.8875 & 0.1125 & -7.89 & $\mathbf{0 . 0 8 0 3}$ \\
Gun traverse speed $\times$ Substrate & -0.1375 & 0.1125 & -1.22 & 0.4365 \\
temperature & & & & \\
Spray angle $\times$ Gun traverse speed & -0.1125 & 0.1125 & -1.00 & 0.5000 \\
Substrate temperature $(0,200)$ & 0.0125 & 0.1125 & 0.11 & 0.9296 \\
Spray angle $\times$ Substrate temperature & -0.0125 & 0.1125 & -0.11 & 0.9296 \\
Spray angle $(0,15)$ & -0.0125 & 0.1125 & -0.11 & 0.9296 \\
\hline
\end{tabular}

Significant parameter is given in bold

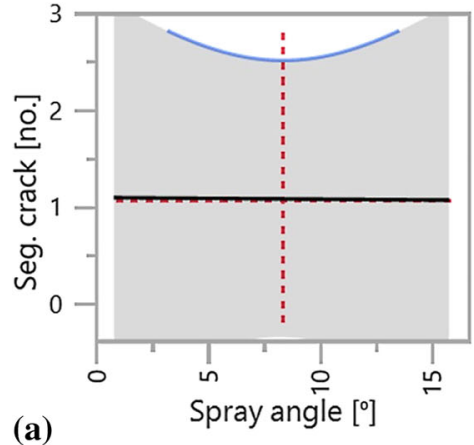

(a)

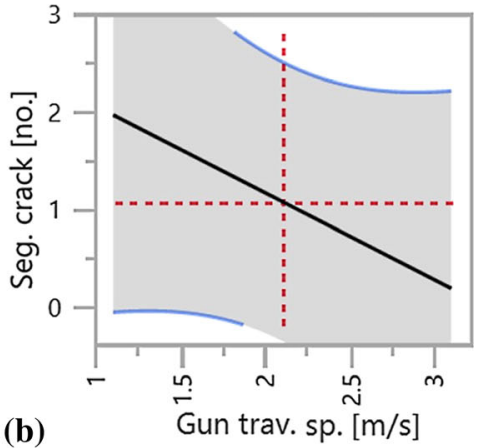

(b)

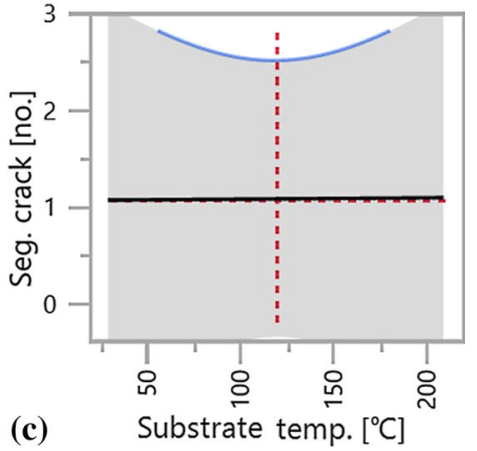

Fig. 8 Prediction profiler of direct splat-affecting parameters on the formation of segmentation cracks
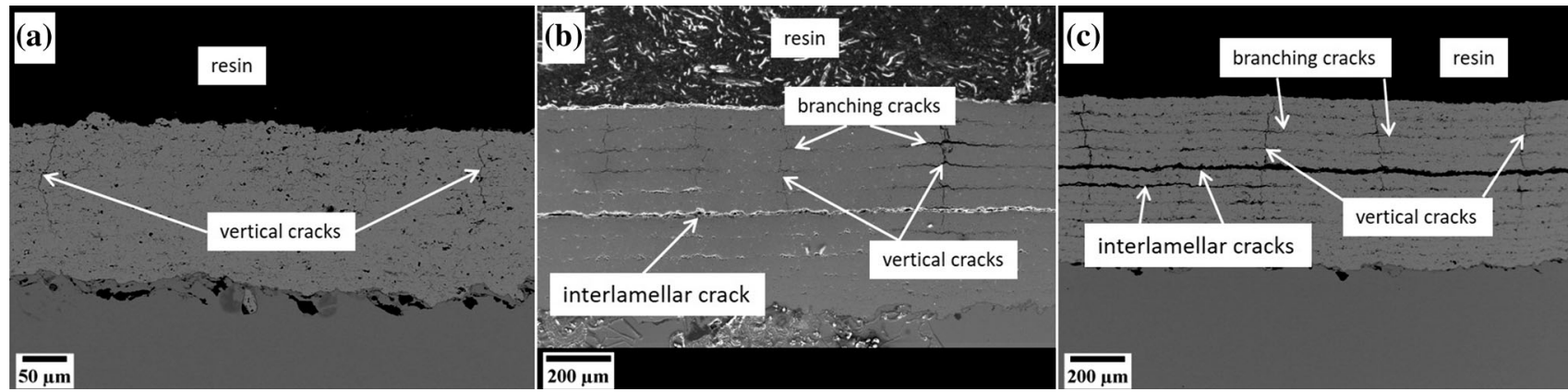

Fig. 9 Cross-sectional SEM images showing different densities of segmentation cracks: (a) 0.5 cracks $/ \mathrm{mm}$ for case 2 , (b) $2.0 \mathrm{cracks} / \mathrm{mm}$ for case 1 , and (C) $2.5 \mathrm{cracks} / \mathrm{mm}$ for case 5

a large number of fully molten splats eligible to form long, thick, and well-bonded layers with vertical cracks penetrating almost the whole thickness of the coating. The effect of the surface velocity of the spray gun and the secondary effect of the substrate temperature on the generation of segmentation cracks is not in line with the literature data (Ref 6,23), in which the strong effect of substrate temperature on the generation of segmentation cracks has been reported.

Figure 9 shows cross-sectional SEM images for coatings sprayed with different surface velocities of the spray gun on cold and hot substrates having different densities of segmentation cracks $(0.5-2.5 \mathrm{cracks} / \mathrm{mm})$ as well as a wide range of thicknesses $(180-640 \mu \mathrm{m})$, even though the same process parameters, including the number of spray passes, were used. The coating shown in Fig. 9a (case 2) has been deposited with a high surface velocity of the spray gun on a cold substrate; therefore, its cross-section shows a very low number of segmentation cracks, with an average of 0.5 cracks $/ \mathrm{mm}$, and low thickness $(\approx 180 \mu \mathrm{m})$. The effect of the surface velocity of the spray gun parameter on the density of segmentation cracks and coating thickness is observable in all coatings from cases 2, 4, 7, and 8. Most of the observed vertical cracks have a length of half of the 
coating thickness or more. Therefore, they are accounted for as segmentation cracks, and, as usual, they are accompanied by very short horizontal cracks. The decrease in these coating thicknesses is linked to the low number of fully molten particles that impinge on the substrate surface per unit area as the spray gun passes at a high speed.

In contrast, the coating shown in Fig. 9b (case 1), which was deposited with a low surface velocity of the spray gun on a cold substrate, possesses a relatively large number of segmentation cracks with an average of 2.0 cracks $/ \mathrm{mm}$ as well as a high coating thickness $(\approx 640 \mu \mathrm{m})$. In this case, a large interlamellar crack is formed at almost the middle of the coating thickness due to the large temperature drop through the coating thickness, which is mainly increased during the deposition (Ref 4). Therefore, it is recommended to decrease the number of spray gun passes so that the coating thickness remains below $500 \mu \mathrm{m}$ (the range of $350-450 \mu \mathrm{m}$ is suitable). Despite the presence of the interlamellar crack, the segmentation cracks continue to penetrate the whole thickness of the coating up to the coating surface. The latter description is also correct for the coating produced with the parameter set 3 (case 3). However, coatings produced with a low surface velocity of the spray gun on hot substrates (cases 5 and 6) showed a comparable density of segmentation cracks ( 2.5 cracks/ $\mathrm{mm})$ and coating thickness $(\approx 540 \mu \mathrm{m})$ to that observed in the coatings deposited with a low surface velocity of the spray gun on a cold substrate (cases 1 and 3). Figure 9c displays a cross-section for the coating sprayed with the parameter set 5 (case 5). This result emphasizes the significant role of the surface velocity of the spray gun parameter in the generation and density of segmentation cracks as well as coating thickness.

Table 5 shows that the effect of the surface velocity of the spray gun and substrate temperature parameters on the coating thickness qualify as significant since their $P$ values are less than 0.05. The graph in Fig. 10 reveals the relationship between coating thickness and direct splat-affecting parameters where the thickness of the coating is increased as the surface velocity of the spray gun and substrate temperature are decreased.

The effect of the spray angle, as well as all parameter interactions, have a very low effect on the coating thickness and, therefore, they can be ignored. The increase in coating thickness is attributed to the large number of fully molten particles that impinge on the substrate surface per unit area, due to the low surface velocity of the spray gun. Moreover, if the deposition was on a cold substrate, fully molten particles tend to form distorted-splat type where higher levels of porosity are obtained and, as a consequence, the coating thickness increased.

\section{Summary and Conclusion}

In the present work, the influences of direct splat-affecting parameters (i.e., spray angle, surface velocity of the spray gun, and substrate temperature) on the splat-type distribution, the coating porosity, the coating thickness, and the generation of segmentation cracks were investigated. The investigations were made on samples prepared from 8 experiments that are based on a $2^{3}$ full factorial design technique. According to the measurements and results obtained, the following conclusions can be drawn:

1. Depositing fully molten particles on a hot substrate increases the fraction of disk-like splats at the expense of the fraction of distorted splats. Up to $60 \%$ of distorted splats can be transitioned to disk-like type if the deposition is made on a preheated substrate at about $200{ }^{\circ} \mathrm{C}$. In contrast, shifting the spray angle from the normal position increases the fraction of distorted splats at the expense of the fraction of the disk-like type. Up to $20 \%$ of disk-like splats are distorted as a result of shifting the spray angle by $15^{\circ}$. The surface velocity of the spray gun has almost no effect on splattype distribution.

2. The effect of the substrate temperature and surface velocity of the spray gun on the level of coating
Table 5 Effect significance of direct splat-affecting parameters on the coating thickness

\begin{tabular}{lllcr}
\hline \multicolumn{1}{c}{ Term } & Estimate & SE & $t$ ratio & Prob $>|t|$ \\
\hline Effect report: coating thickness & & & & \\
Gun traverse speed $(1.0,3.0)$ & $\mathbf{- 2 1 0 . 7 5}$ & 1.75 & $\mathbf{- 1 2 0 . 4}$ & $\mathbf{0 . 0 0 5 3}$ \\
Substrate temperature $(0,200)$ & $-\mathbf{2 7}$ & 1.75 & $-\mathbf{1 5 . 4 3}$ & $\mathbf{0 . 0 4 1 2}$ \\
Gun traverse speed $\times$ Substrate & 20.25 & 1.75 & 11.57 & 0.0549 \\
temperature & & & & \\
Spray angle $\times$ Gun traverse speed & -7.75 & 1.75 & -4.43 & 0.1414 \\
Spray angle $\times$ Substrate & -4 & 1.75 & -2.29 & 0.2625 \\
temperature & -3 & & & -1.71 \\
Spray angle $(0,15)$ & & & & 0.3362 \\
\hline
\end{tabular}

Significant parameters are given in bold 


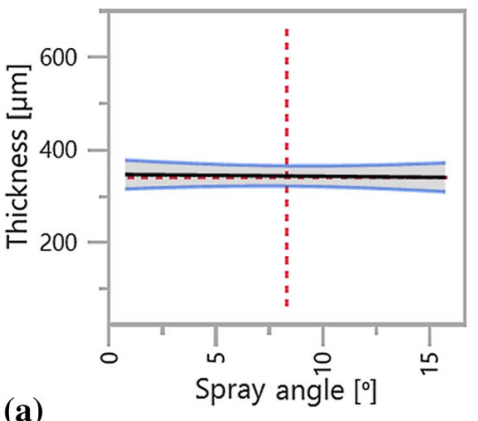

(a)

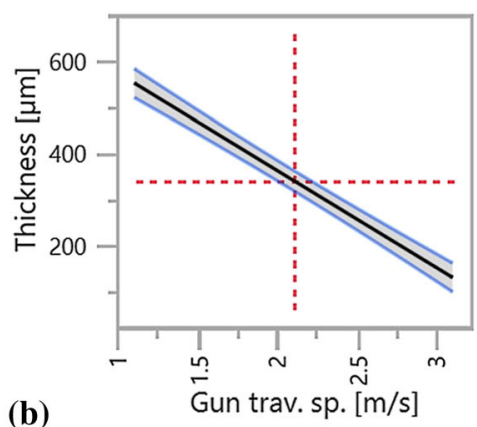

(b)

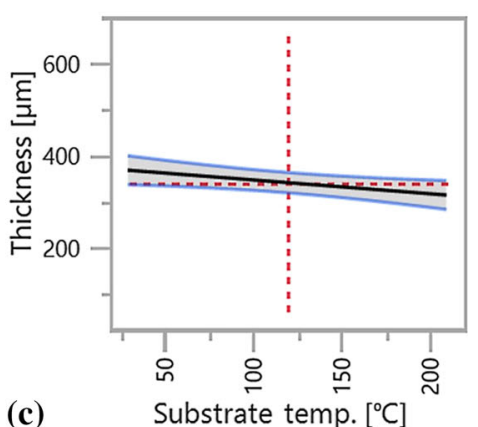

(c)

Fig. 10 Prediction profiler of direct splat-affecting parameters on the coating thickness

porosity can be seen. The porosity level is increased whenever the substrate temperature or surface velocity of the spray gun or both are increased. Conversely, shifting the spray angle leads to a slight decrease in the level of coating porosity; hence, it is considered an insignificant factor. Analysis of the pore information reveals the same effect of the three parameters on the pore count.

3. The surface velocity of the spray gun is the most significant factor affecting the formation and density of segmentation cracks as well as the coating thickness. Depositing with a low surface velocity of the spray gun led to generating segmentation cracks up to 3 cracks/ $\mathrm{mm}$. In addition, the substrate temperature has a pronounced effect on the coating thickness. Depositing on cold substrates further increases the coating thickness.

In summary, the indirect splat-affecting parameters (plasma arc current, standoff distance, and flow of the plasma gas mixture) were selected so that the ceramic particles are deposited at a high melting degree. These were fixed during the experiments for the present work while varying the direct splat-affecting parameters (spray angle, surface velocity of the spray gun, and substrate temperature). Based on the results of this work, spray sets 5 and 6 have produced coatings that possess relatively the highest density of segmentation cracks and acceptable levels of porosities. Therefore, they were selected for further investigations. The quality of the coatings (cases 5 and 6) can be further enhanced by varying the surface velocity of the spray gun parameter since it plays the main role in coating consistency as well as generating the segmentation cracks. Additionally, an appropriate number of spray passes should be considered to avoid increased coating thickness. A high number of spray passes leads to create large interlamellar cracks between the upper and lower layers of the deposition.
Acknowledgments The authors gratefully acknowledge the financial support by the German Research Foundation (DFG) under Grant No. TI 343/157-1.

Funding Open Access funding enabled and organized by Projekt DEAL.Open Access This article is licensed under a Creative Commons Attribution 4.0 International License, which permits use, sharing, adaptation, distribution and reproduction in any medium or format, as long as you give appropriate credit to the original author(s) and the source, provide a link to the Creative Commons licence, and indicate if changes were made. The images or other third party material in this article are included in the article's Creative Commons licence, unless indicated otherwise in a credit line to the material. If material is not included in the article's Creative Commons licence and your intended use is not permitted by statutory regulation or exceeds the permitted use, you will need to obtain permission directly from the copyright holder. To view a copy of this licence, visit http://creativecommons.org/licenses/by/4.0/.

\section{References}

1. S. Sampath and X. Jiang, Splat Formation and Microstructure Development During Plasma Spraying: Deposition Temperature Effects, Mater. Sci. Eng. A, 2001, 304, p 144-150.

2. R.A. Miller, Thermal Barrier Coatings for Aircraft Engines: History and Directions, J. Therm. Spray Technol., 1997, 6, p 3542.

3. N. Curry, Design of Thermal Barrier Coatings, A Modeling Approach, 2014, 3.

4. H.B. Guo, R. Vaßen, and D. Stöver, Atmospheric Plasma Sprayed TBCs with High Segmentation Crack Density, Surf. Coat. Technol., 2004, 186, p 353-363.

5. M. Karger, R. Vaßen, and D. Stöver, Atmospheric Plasma Sprayed Thermal Barrier Coatings with High Segmentation Crack Densities: Spraying Process, Microstructure, and Thermal Cycling Behavior, Surf. Coat. Technol., 2011, 206, p 16-23.

6. H.B. Guo, R. Vaßen, and D. Stöver, Thermophysical Properties and Thermal Cycling Behavior of Plasma-Sprayed Thick Tbcs, Surf. Coat. Technol., 2005, 192, p 48-56. 
7. P. Bengtsson, T. Ericson, and J. Wigren, Thermal Shock Testing of Burner Cans Coated with a Thick Thermal Barrier Coating, $J$. Therm. Spray Technol., 1998, 7, p 340-348.

8. H. Herman, Plasma-sprayed coatings, Sci. Am., 1988, 259(3), p 112-117.

9. S. Sampath et al., Substrate Temperature Effects on Splat Formation Microstructure Development and Properties of PlasmaSprayed Coatings Part: A Case Study for Partially Stabilized Zirconia, Mater. Sci. Eng., 1999, 272(1), p 181-188.

10. P. Fauchais et al., Knowledge Concerning Splat Formation: An Invited Review, J. Therm. Spray Technol., 2004, 13(3), p 337360.

11. J.M. Houben, PhD Thesis, University of Eindhoven, Netherlands, 1988.

12. C.J. Li, A. Ohmori, Y. Harada, and A. Ohmori (Ed.), Proc. of the International Thermal Spray Conference, Kobe, Japan, May 1995, Japan High Temperature Society, Japan, 1995, pp 333-339.

13. M. Vardelle, A. Vardelle, A.C. Leger, and P. Fauchais, Thermal Spray Industrial Applications. C.C. Berndt, S. Sampath Ed., ASM Int, Metals Park, OH, 1994, p 555-562

14. M. Mutter et al., Correlation of Splat Morphologies with Porosity and Residual Stress in Plasma-Sprayed YSZ Coatings, Surf. Coat. Technol., 2017, 318, p 157-169.

15. M. Mutter, G. Mauer, R. Mücke, O. Guillon, and R. Vaßen, Systematic Investigation on the Influence of Spray Parameters on the Mechanical Properties of Atmospheric Plasma-Sprayed YSZ Coatings, J. Therm. Spray Technol., 2018, 27, p 566-580.

16. M. Mutter et al., Investigations on the Initial Stress Evolution During Atmospheric Plasma Spraying of YSZ by In-Situ Curvature Measurement, J. Therm. Spray Technol., 2016, 25(4), p 672-683.

17. R.C. Dykhuizen, Review of Impact, and Solidification of Molten Thermal Spray Droplets, J. Therm. Spray Technol., 1994, 3(4), p 351-361.

18. L. Bianchi, F. Blein, P. Lucchese, M. Vardelle, A. Vardelle, and P. Fauchais, Thermal Spray Industrial Applications. C.C. Berndt, S. Sampath Ed., ASM Int, Metals Park, OH, 1994, p 569

19. M. Fukumoto, S. Katoh, I. Okane, and A. Ohmori (Ed.), Proceedings of International Thermal Spray Conference, Kobe, Japan: Japan High Temperature Society, 1995, p. 353.

20. Y.P. Wan et al., Role of Solidification, Substrate Temperature, and Reynolds Number on Droplet Spreading in Thermal Spray Deposition: Measurements and Modeling, J. Heat Transf., 2001, 123(2), p 382-389.

21. G. Qian, T. Nakamura, C.C. Berndt, and S.H. Leigh, Tensile Toughness Test, and High-Temperature Fracture Analysis of TBCs, Acta Mater., 1997, 45(4), p 1767-1784.

22. J.T. DeMasi-Marcin, K.D. Sheffler, and S. Bose, Mechanisms of Degradation and Failure in a Plasma-Deposited TBC, J. Eng. Gas Turb. Power, 1990, 112, p 521-526.

23. M. Friis, C. Persson, and J. Wigren, Influence of Particle in-Flight Characteristics on the Microstructure of Atmospheric PlasmaSprayed Yttria-Stabilized $\mathrm{Zro}_{2}$, Surf. Coat. Technol., 2001, 141, p 115-127.

24. H. Guo, H. Murakami, and S. Kuroda, Thermal Cycling Behavior of Plasma-Sprayed Segmented Thermal Barrier Coatings, Mater. Trans., 2006, 47, p 306-309.
25. T.A. Taylor, Thermal Barrier Coatings for Substrates and Process for Producing it, US Patent 5,073,433, 1991.

26. M. Fukumoto and Y. Huang, Flattening Mechanism in Thermal Sprayed Nickel Particle Impinging on a Flat Substrate Surface, $J$. Therm. Spray Technol., 1999, 8(3), p 427-432.

27. T. Chraska and A.H. King, Effect of Different Substrate Conditions upon Interface with Plasma-Sprayed Zirconia-A TEM Study, Surf. Coat. Technol., 2002, 157(2-3), p 238-246.

28. G. Montavon et al., Effects of the Spray Angle on Splat Morphology During Thermal Spraying, Surf. Coat. Technol., 1997, 91(1-2), p 107-115.

29. A.A. Kulkarni et al., Advanced Microstructural Characterization of Plasma-Sprayed Zirconia Coatings over Extended Length Scales, J. Therm. Spray Technol., 2005, 14(2), p 239-250.

30. A.C. Leger, M. Vardelle, A. Vardelle et al., Plasma-Sprayed Zirconia: Relationships between Particle Parameters, Splat Formation, and Deposit Generation-Part I: Impact and Solidification, 9th NTSC, Cincinnati, Ohio, USA, October 1996, ASM International, Materials Park, OH, USA, ASM Int., Mat. Park, 1994, pp 623-628.

31. A. Syed, A. Denoirjean, B. Hannoyer, P. Fauchais, P. Denoirjean, A. Khan, and J. Labbe, Influence of Substrate Surface Conditions on The Plasma Sprayed Ceramic and Metallic Particles Flattening, Surf. Coat. Technol., 2005, 200(7), p 2317-2331.

32. X.Y. Jiang, J. Matejicek, A. Kulkarni, H. Herman, S. Sampath, D.L. Gilmore, and R.A. Neiser, Process Maps for Plasma Spray Part II: Deposition and Properties, in C.C. Berndt (Ed.), Therm. Spray Surf. Eng., 2000, p 157.

33. S. Sampath, X. Jiang, A. Kulkarni, J. Matejicek, D.L. Gilmore, and R.A. Neiser, Development of Process Maps for Plasma Spray: A Case Study for Molybdenum, J. Mater. Sci. Eng., 2003, 348(1), p 54-66.

34. R. Dhiman, A.G. McDonald, and S. Chandra, Predicting Splat Morphology in a Thermal Spray Process, Surf. Coat. Technol., 2007, 201(18), p 7789-7801.

35. N. Sakakibara, H. Tsukuda, and A. Notomi, The Splat Morphology of Plasma-Sprayed Particle and the Relation to Coating Property, Therm. Spray Surf. Eng. Appl. Res. ASM Int., 2000, 6, p 753-758.

36. G. Montavon, S. Sampath, C. Berndt, H. Herman, and C. Coddet, Effects of the Spray Angle on Splat Morphology during Thermal Spraying, Surf. Coat. Technol., 1997, 91(1-2), p 107-115.

37. W. Tillmann, O. Khalil, and I. Baumann, Influence of Spray Gun Parameters on Inflight Particle's Characteristics, the Splat-Type Distribution, and Microstructure of Plasma-Sprayed YSZ Coatings, Surf. Coat. Technol., 2021 https://doi.org/10.1016/j.surf coat. 2020.126705

38. W. Tillmann, B. Hussong, T. Priggemeier, S. Kuhnt, N. Rudak, and $\mathrm{H}$. Weinert, Influence of Parameter Variations on WC-Co Splat Formation in an HVOF Process Using a New Beam-Shutter Device, J. Therm. Spray Technol., 2013, 22, p 250-262.

39. W.S. Rasband, ImageJ, U. S. National Institutes of Health, Bethesda, MD, USA, https://imagej.nih.gov/ij/, 1997-2020. Accessed 24.September 2020.

Publisher's Note Springer Nature remains neutral with regard to jurisdictional claims in published maps and institutional affiliations. 